doi: $10.12957 /$ childphilo.2020.48283

\title{
ação de desenhar na infância como iniciação aos segredos do mundo
}

\author{
sandra regina simonis richter ${ }^{1}$ \\ universidade de santa cruz do sul, brasil \\ orcid id: https:/ / orcid.org/0000-0002-7902-5918 \\ márcia vilma murillo² \\ universidade de santa cruz do sul, brasil \\ orcid id: https:/ / orcid.org/0000-0001-6437-9724
}

Para destacar a íntima relação entre imaginar, desenhar e produzir mundos este ensaio interroga o sentido educacional das crianças iniciarem-se na ação de desenhar diante da crescente tendência cultural de ser o corpo cada vez menos exigido a produzir sentidos. A ação encarnada de desenhar, como ação estésica de tocar e ser tocado pelo mundo ao transpor os limites visíveis e adentrar na intimidade da invisibilidade mundana, constitui experiência tão recorrente e banalizada no cotidiano escolar quanto existencialmente complexa pela sua potência poética de adentrar o invisível e inaugurar visões de mundos. A histórica desqualificação da imagem e da imaginação no pensamento ocidental, dada pela cisão entre subjetividade do corpo e objetividade do mundo, não permite ao pensamento educacional considerar o fenômeno da imaginação poética como experiência existencial de inserção linguageira no mundo a partir do gesto de desenhar. Gesto que encontra sua especificidade no instante realizador da mão que traça e inscreve linhas na superfície dos suportes como escritura infinitamente inventável. $\mathrm{O}$ gesto estésico de desenhar, temporalizado pelo ritmo do corpo na emergência da fabulação que acompanha a repetição das marcas, implica uma experiência poética de linguagem que envolve a fusão de dois sentidos: o do gesto na materialidade e o da marca nela configurada, cicatrizada na superfície do suporte pela ação do corpo que a realizou. A aproximação entre educação, artes e infância permite destacar as tensões filosóficas e pedagógicas que envolvem a questão da imaginação poética e lançar outro olhar à ação de desenhar no âmbito da educação das crianças. O que emerge, a partir da interlocução entre Gaston Bachelard, Maurice Merleau-Ponty e Jean-Luc Nancy, é a relevância da intenção educativa do cuidado com a função vital da linguagem como experiência estésica e poética que se constitui na processualidade do corpo fazer aparecer algo que produza e contenha presença, aquela que promove e amplia a densidade existencial do real.

palavras-chave: educação infantil; imaginação poética; desenhar; experiência de linguagem; mundo.

\section{acción de dibujar en la infancia como iniciación a los secretos del mundo}

Para resaltar la íntima relación entre imaginar, dibujar y producir mundos, este ensayo cuestiona el sentido educacional de niños se iniciaren en la acción de dibujar frente a la creciente tendencia cultural del cuerpo ser cada vez menos exigido para producir sentidos. La acción encarnada del dibujar, como una acción estésica de tocar y ser tocado por el mundo al trasponer los límites visibles y adentrar en la intimidad invisiblemente mundana, se constituye en una experiencia recurrente y trivializada del cotidiano escolar, así como existencialmente compleja por su potencia poética de adentrar en lo invisible e

\footnotetext{
1 E-mail: s12richter@gmail.com

2 E-mail: marciamurillo@gmail.com
} 
ação de desenhar na infância como iniciação aos segredos do mundo

inaugurar cosmovisiones. La histórica descalificación de la imagen y de la imaginación en el pensamiento occidental, dada por la cisión entre subjetividad del cuerpo y objetividad del mundo, no permite al pensamiento educacional considerar el fenómeno de la imaginación poética como una experiencia existencial de inserción de lenguaje en el mundo a partir del gesto de dibujar. Gesto temporalizado por el ritmo del cuerpo en la emergencia de fabulación que acompaña la repetición de marcas, gesto que también implica en una experiencia poética de lenguaje que envuelve la fusión de dos sentidos: del gesto en la materialidad y de marca en ella configurada, cicatrizada en la superficie de soporte por la acción del cuerpo que la realizó. La aproximación entre educación, artes e infancia permite resaltar las tensiones filosóficas y pedagógicas que envuelven la cuestión de imaginación poética y volver la mirada a la acción de dibujar en el ámbito de educación de niños y niñas. Lo que emerge, desde la interlocución entre Gaston Bachelard, Maurice Merleau-Ponty e Jean-Luc Nancy, es la relevancia de una intención educativa de cuidado para con la función vital del lenguaje como experiencia estética y poética que se constituye en el carácter procesal del cuerpo para hacer aparecer algo que produzca y contenga presencia, aquello que promueve y expande la densidad existencial de lo real.

palabras clave: educación infantil; imaginación poética; dibujar; experiencia de lenguaje; mundo.

\section{drawing in childhood as initiation to the secrets of the world}

In order to highlight the intimate relationship between imagining, drawing and making worlds, this essay questions the educational meaning of initiating children into the action of drawing, in the face of the growing cultural tendency of the body being less and less required to produce sensuous meaning. The incarnated action of drawing, as an aesthetic action of touching and being touched by the world when transposing the visible limits and entering into the intimacy of worldly invisibility, constitutes an experience that is as recurrent and trivialized in school daily life as it is existentially complex due to its poetic power to enter the invisible and inaugurate worldviews. The historical disqualification of the image and of imagination in Western thought, supported by the separation between the subjectivity of the body and the objectivity of the world, does not allow educational thought to consider the phenomenon of poetic imagination as an existential experience of language's insertion in the world by way of the gesture of drawing. This gesture finds its specificity in the instant the hand traces and inscribes lines on a surface. The aesthetic gesture of drawing, temporalized by the rhythm of the body in the emergence of the fabulation that accompanies the repetition of lines, implies a poetic experience of a language that involves the fusion of two senses: that of the material gesture and that of the mark configured by that gesture--marked and cicatrized on the surface by the body's action that performed it. The approximation between education, art and childhood allows us to highlight the philosophical and pedagogical tensions that involve the question of poetic imagination, and to take another look at the action of drawing in the context of children's education. What emerges, from the dialogue between Gaston Bachelard, Maurice Merleau-Ponty and Jean-Luc Nancy, is the relevance of the educational intention of caring for the vital function of language as an aesthetic and poetic experience that is constituted in the of the body by making something appear that produces and contains presence, and which promotes and expands the existential density of the real.

key words: early childhood education; poetic imagination; drawing; language experience; world. 
ação de desenhar na infância como iniciação aos segredos do mundo

Desenhar é um gesto expressivo, mas com a vantagem da permanência.

Matisse (2004, p.12)

Aproximamos nossos estudos em torno da imaginação poética na educação de crianças para nos determos na íntima relação entre imaginar, desenhar e produzir mundos a partir do interesse intelectual pelo movimento vital - tão singular quanto plural - de tornar-se operador fabuloso da e na linguagem. É o mistério da linguagem, o enigma do fenômeno do sensível e da experiência da estesia como vínculo vital entre corpo e mundo, que nos interroga e nos faz enfrentar na e com a escrita a fecunda tensão filosófica entre real e ficcional, entre pensamento imagético e pensamento conceitual. Uma antiga tensão não apenas no campo educacional, mas também nos campos da ética e da estética, por definir uma disputa política para dizer como é o mundo, como nele consumamos ações e legitimamos narrativas na coexistência mundana.

As experiências iniciais de desenhar, assim como de escrever, pintar, dançar, modelar, cantar, remetem à singularidade lúdica das crianças realizarem sua inserção cultural na pluralidade mundana das imagens e das palavras, dos devaneios e das fabulações, das ideias e dos conceitos. Evento de linguagem que as instala e as orienta nas interações e no real por ser experiência existencial que nos situa em relação às coisas e nos faz habitar o mundo comum como produção de coexistência. Aqui, a magnitude existencial do fenômeno de começar-se em linguagem reivindica ao pensamento educacional tanto escuta à alteridade linguageira entre adultos e crianças quanto consideração pela potência lúdica do corpo aprender a começar-se em linguagem na íntima relação entre provocações à imaginação e desafios à razão.

Todos - crianças e adultos - desenham com qualquer instrumento em qualquer suporte. De algum modo, todos podem riscar e rabiscar linhas ao tracejar um plano de trabalho, ao delinear diagramas para refletir um problema, ao esquematizar um trajeto na cidade, ao configurar mapas, projeções ou cenários 
ação de desenhar na infância como iniciação aos segredos do mundo

para visualizar uma ideia ou propor visões. O traço, ao tornar visível a ação do gesto pelo ato de desenhar, se mostra instantaneamente em uma figuração definida pelos seus modos de aparecer. Em outras palavras, a figuração dá a ver a existência óptica de algo. Nesse sentido, o traçado em linhas no suporte não nos mostra uma aparência ilusória, mas a ilusão de uma aparência que permite amplificar o real tanto no plano técnico ${ }^{3}$ e científico como no artístico ao possibilitar passar do plano oculto ou intangível ao plano disto que é mostrado, tornado visível (Richter, 2005).

Tanto as artes como as ciências recorrem aos mesmos meios em sua conquista de compreensão e instauração de realidades: com alguns traços podem contrair a imensidão do mundo não apenas para traduzir sua profundidade como para alcançar a multiplicidade de horizontes que amplificam e favorecem sua aproximação através da apropriação do real pela instauração de sua inteligibilidade. Tornar visível o mundo pela ação de desenhar exige a redução das distâncias, isto é, exige reduzir o mundo para trazê-lo inteiro pelo olhar e, assim, torná-lo tangível para dominá-lo com a mão artesã. Basta o gesto que desenha (ou pinta ou modela ou constrói) para fazer um mundo reduzido tornarse figuração do mundo, microcosmo que se pode envolver pelo olhar e trazer pela mão artesão a grandeza do conjunto.

Desenhar ou colocar em imagens o halo de visibilidade do não visto ainda pelos sentidos do corpo vidente que se vê a si mesmo vendo é, para MerleauPonty (2004), ato de nascer para as coisas como ato de misturar-se ao mundo. Esse ato de misturar-se à "visibilidade profana" (Merleau-Ponty, 2004) da luz, da cor, dos reflexos, das sombras exige uma visibilidade inteira a ser recriada no corpo, pois "não se trata de falar do espaço e da luz, e sim de fazer falarem o espaço e a luz que estão aí" (Merleau-Ponty, 2004, p. 33). Essa é a complexidade da ação de desenhar desde as primeiras experiências de riscar e rabiscar em algum suporte que receba a inscrição de um gesto.

\footnotetext{
${ }^{3}$ Para Galimberti (2006, p. 87), o pacto original entre corpo e mundo que o gesto evidencia, é a condição de onde parte o agir técnico, que permite ao humano, de per si inapto para o mundo, constituir um mundo possível.
} 
Nessa compreensão, a pluralidade das possibilidades de estar em linguagem no tempo e espaço escolares não são passíveis de serem simplificadas. Especialmente se considerarmos que é aí, neste espaço e neste tempo educacional, que são instituídos e reproduzidos possibilidades e hábitos de habitar o mundo, de estar nas palavras e nas imagens. A introdução e inserção escolar aos hábitos de linguagem tendem ao esquecimento que não há pensamento que não se articule em gesto em seus efeitos-mundo, que o pensamento conceitual não se opõe ao pensamento imagético, antes razão e imaginação são complementares em suas possibilidades "criadoras", "ativas", "abertas" e "realizantes" (Bachelard, 2004). O esquecimento do corpo sensível como como fonte primeira de sentidos e significados que nos instalam no mundo impõe interrogar, com Jean-Luc Nancy (2019, p. 96), “como nos relacionamos com o mundo quando no fundo estamos completamente divididos entre o inteligível e o sensível?"

Talvez, a tarefa educacional por vir esteja no ato de resistência ao desencantamento que vivemos diante da crescente aridez utópica que assola a convivência. Banalidades emergem, trivialidades vigoram pelo sentimento de segurança que a certeza do realismo visual proporciona. Para resistir à crescente tendência de simplificação progressiva da existência pela simplificação das experiências sensíveis do inteligível aproximamos filosofia, artes e infância para interrogarmos concepções em torno do ato de desenhar diante do paradoxo de constituir uma experiência estésica tão recorrente e banalizada no cotidiano escolar quanto existencialmente complexa se considerarmos sua potência poética de inaugurar mundos.

Nosso interesse em lançar outro olhar à ação de desenhar, um olhar marginal ou à sombra de outra tradição no âmbito da educação escolar das crianças, está em resistir à concepção hegemônica tanto de imagem e de visão como identificação de uma realidade representada em função da ordem do conhecimento objetivo, mera ilustração do mundo como espelho do real, quanto de imaginação como a "louca da casa"4 em seus perigos à racionalidade de desviar o olhar e expor os porões escuros e recônditos da percepção, portanto falsa,

\footnotetext{
${ }^{4}$ Expressão referida por Nicolas Malebranche (1638-1715), padre francês e filósofo racionalista do século XVII.
} 
ação de desenhar na infância como iniciação aos segredos do mundo

delirante ou "livremente" distanciada da realidade do mundo. Em outras palavras, o que neste ensaio resistimos é à hegemônica tendência de priorizar a dimensão cognitiva do desenho em seus resultados escolares, exigidos a remeterem a um mundo designado e formulado em palavras, passível de ser esgotado pela análise e pela explicação que substituem a imagem pelo signo.

Esta gestão escolar da ação de desenhar das crianças, ritmada pelo primado do conhecimento sobre o gesto heurístico, da prioridade de explicar imagens em detrimento do pensamento imagético, ou seja, de receber ou consumir figurações sobre a ação de as produzir, apresenta certa constância ontem como hoje. Prioridades que tornam hegemônica a objetividade da percepção como análise ou explicação - em detrimento da temporalidade ou do processo gestual - estésico e poético - de fazer aparecer algo no mundo como ato sensível e inteligível de tocálo ao ser por ele tocado no ato de instaurar imagens para partilhar $^{5}$ sensações e sentidos que, antes de significar, valoram a convivência. Se consideramos que o sentido "passa entre nós, e não entre significante, significado e referente" (Nancy, 2003, p. 62), pois diz respeito à apresentação ou vinda à presença, não há aqui soluções a investigar ou modelos a sugerir, mas uma questão - a da ação de desenhar como experiência mundana de linguagem - a enfrentar e interrogar no campo da educação escolar.

Nesse sentido, lançamos um convite a considerar com mais atenção - e maior paixão - "a ação que faz do que a coisa feita" (Valèry, 1999, p. 181), ou então, a processualidade da "fabricação", do fazer e seus modos de apresentar seus truques, sua maneira de fazer sentido, em suma, sua relação lúdica com o mundo, seu exercício experimental de redimensionar o vivido em traços e figurações. Não se trata da ideia de criação. Para Castro (2009, p. 51), o verbo figurar é preciso e fundante, pois trata-se de um fingere - no sentido do termo latino fingo ${ }^{6}$, origem etimológica do termo ficção, que significa fingir, figurar,

\footnotetext{
5 Partimos do termo francês "partage", concebido por Nancy (2016) tanto no sentido de "partilha" como no de "partição" - tanto compartilhar quanto repartir, separar, para com ele afirmar que somente um corpo separado pode tocar, pois tocar começa "quando dois corpos se distanciam e se distinguem um do outro" (Nancy, 2017, p. 16).

${ }^{6}$ Fingere vem do verbo latino fingo [is, ere, finxi, fictum]: modelar em barro; modelar em qualquer substancia plástica, formar, representar, esculpir; imaginar, inventar, fingir; ficção. (Conforme Dicionário de Latim-Português, Porto Editora). Fingere remete à ficção e ao fingir e fingir ao fazer.
} 
formatar, modelar o barro com as mãos - que se traduz por dar-lhe figura, isto é, há uma ação poética como figurar. Castro $(2009$, p. 51) destaca que este verbo não diz de modo algum o mesmo que formar, pois figuração não traduz um pensamento já feito, mas o consuma. Para o autor, no figurar algo advém do vazio à presença. Há aqui uma ligação temporal profunda entre presença e presente. Assim, o verbo fazer é por nós compreendido na ordem do ficcional na qual as decisões têm que ser tomadas no percurso entre o instante da escolha do gesto inicial e o instante do gesto final, como energia poética capaz de rearranjar as relações entre o que se faz e o que se pode fazer.

Neste ensaio em torno da ação de desenhar como entrelaçamento entre corpo e mundo lançamos um convite para acolher a intimidade que o gesto poético de desenhar estabelece com as propriedades mundanas dos materiais e dos suportes. Assim como a tatuagem é inseparável da pele, também a ação de desenhar, por ser incisão na materialidade do suporte, é indissociável dela e do modo como nele faz aparecer as inscrições das marcas. Por outro lado, também exige acolher a profunda interconexão entre desenhar, realizar colagens, pintar, gravar, modelar, num entrecruzamento contínuo entre fronteiras e categorias artísticas estabelecidas.

Aqui, prévias definições de desenho ou de como desenhar não vigoram se concebemos que desenhar é inventar uma escritura que instaura visibilidades por um olhar "que foi comovido por um certo impacto do mundo, e que o restitui ao visível pelos traços da mão" (Merleau-Ponty, 2004, p. 91). Desenhar, como celebração do enigma da visibilidade, é gesto de misturar-se ao mundo no ato mesmo de traçar, marcar, registrar uma "expressão de mundo" que se mostra ao nos interrogar a "gênese secreta e febril das coisas em nosso corpo" (MerleauPonty, 2004, p. 93).

Desenhar, por constituir um gesto estésico que implica simultaneamente especulação do acaso e projeção de intenções, repetição e sobreposição de linhas, experimentação e controle, é gesto infinitamente inventável. A experiência poética de desenhar - ou pintar, modelar, gravar - diz respeito à errância contida no percurso temporal do gesto, no qual a cada instante é exigido tomar decisões, 
ação de desenhar na infância como iniciação aos segredos do mundo

realizar escolhas, apropriações, combinações, transfigurações, que promovem abertura a um espaço ficcional que autoriza efetivar ações arriscadas e rearranjos entre gestos, materialidades e narrativas. Significa afirmar, antes da explicação ou da análise dos desenhos das crianças, a relevância do modo como a inscrição na materialidade do suporte é produzida, ao modo como o ritmo do corpo impõe a cadência da aparição das marcas que surgem ao olhar.

Nessa intenção, propomos compartilhar nossos estudos em torno da relação entre $\mathrm{o}$ ato gestual de desenhar e o fenômeno da imaginação poética para destacarmos a inseparabilidade entre corpo sensível, mundo e experiência de linguagem. Uma abordagem que convida o pensamento educacional a considerar a intencionalidade educativa de resistir à tendência cognitiva de interdição ao corpo sensível que é também "mutilação da linguagem" (Larrosa, 2004, p. 168). Interdição que aponta para uma educação da sensibilidade iconoclasta pautada em um corpo cada vez menos exigido a enfrentar a invisibilidade do mundo pela aliança entre tendência instrumental da educação escolar e o assédio cultural das tecno-imagens que a tudo explicitam.

\section{desenhar como ato estético, poético e politico de partilhar visibilidades}

O desafio educacional, neste ensaio, está em abordar a relação entre imaginação poética e gesto manual de desenhar em tempos virtuais dos ambientes da cibercultura, isto é, em tempos de imagens sintéticas ou inflação de tecnoimagens que implicam a total abstração, ou nos termos do filósofo Vilém Flusser (2008), a nulodimensionalidade. O que daí decorre, para Flusser (1998, p. 29), é a constatação que o humano "não mais decifra as cenas da imagem como significados do mundo, mas o próprio mundo vai sendo vivenciado como conjunto de cenas". A questão, para nós, não é tanto o desmesurado abuso na reprodutibilidade técnica das imagens, mas a desvinculação por ela promovida de nossa corporeidade. Cada vez mais o corpo é menos exigido a produzir sentidos que nos situam na coexistência. Cada vez mais consumimos representações e partilhamos com as crianças a trivialidade do visível em detrimento do prazer sensual que emerge do embate lúdico entre corpo e materialidade do mundo para 
designar - ou desenhar - os possíveis que emergem do gesto de ordenação de sentidos sensíveis e inteligíveis, isto é, dos possíveis que emergem da produção encarnada de mundos, "ao mesmo tempo como forma e como sentido, como linguagem" (Nancy, 2019, p. 94). O que nos faz considerar que, talvez como nunca, é necessário reivindicar a educação da sensibilidade como interrogação à desconsideração educacional do corpo linguageiro como instaurador de mundos.

O sociólogo norte-americano Richard Sennett, para quem “as possibilidades do artesanal radicam precisamente nesta implicação corporal e visceral" (Sennett, 2013, p. 37), observa com preocupação que utilizamos o desenho mecânico produzido pelo computador "como um substituto dos olhos, mais que uma ajuda para desenhar" (Sennett, 2013, p. 37). De outro modo, é o que reafirma o professor Baitello Júnior, pesquisador brasileiro no campo da Comunicação e Semiótica da Cultura, ao sublinhar que a desmedida proliferação de imagens, pelo acesso de sua reprodutibilidade técnica, vem promovendo "o surgimento de uma instância crescente de imagens que se insinuam para serem vistas enquanto decresce em igual proporção a capacidade humana de enxergá-las" (Baitello Júnior, 2014, p. 129). É pelo crescimento exponencial da extrema exposição do visível, dada pela atuação excessiva e descontrolada das tecno-imagens, destacada por Dietmar Kamper (Baitello Júnior, 2014, p. 25) como promotora de uma impossibilidade de ver que emerge "não mais da fadiga do objeto e seus materiais, mas da fadiga do olhar e seu corpo", que consideramos educacionalmente relevante insistir, com Tiburi e Chuí (2010, p. 23), que o ato manual de desenhar "ainda é o lugar do corpo como espaço próprio da experiência".

Esse espaço próprio da experiência que o gesto manual de desenhar instaura é aqui abarcado, com Merleau-Ponty (1999b, p. 156), como iniciação aos segredos do mundo pela interrogação “à nossa experiência7, precisamente para saber como nos abre ela para aquilo que não somos". Portanto, não implica conhecimento, nem aparição de alguma verdade, não é comportamento nem acontecimento para nós. É emergência da opacidade do desconhecido que tem que

\footnotetext{
${ }^{7}$ Merleau-Ponty (VI, p. 156) destaca que não há aqui nenhuma referência a um ego ou a um certo tipo de relações intelectuais com o ser, mas "é à nossa experiência que nos endereçamos - porque toda questão se endereça a alguém ou a alguma coisa, e não podemos escolher interlocutor menos comprometedor que o tudo daquilo que é para nós".
} 
ação de desenhar na infância como iniciação aos segredos do mundo

ser dotado de sentido em nossa corporeidade, reformulado, articulado e narrado para ser encarnado ${ }^{8}$, isto é, compreendido e apropriado em nosso corpo.

Quando em nós negligenciamos nossa corporeidade, dada pela circularidade entre fazer e pensar, "o que resulta prejudicada é a parte intelectual. Isto é, dissociar o âmbito material do analítico tem como consequência uma debilidade intelectual, uma diminuição de nossa capacidade de visão e compreensão" (Sennett, 2013, p. 13). Nessa perspectiva, o que não somos não é o que está além e "fora" de nós, assim como o que somos não é o "dentro" de nós. O que não é nós e o que somos é o sensível como distância tornada estranha proximidade na qual sensibilidade e compreensão emergem misturados aos movimentos do corpo no mundo. Corpo que não apenas desloca-se pois é capaz, nas palavras de Michel Serres (2004, p.139), “de todas as metamorfoses possíveis; se ele não as executa de maneira perfeita, ele sabe, pelo menos, simulá-las ou imitá-las".

Diante da intensidade das interrogações - tão intrigantes quanto instigantes - que envolvem a tensa relação entre corpo sensível e pensamento, as fronteiras disciplinares, assim como as fronteiras acadêmicas entre as distintas artes, não permitem dar conta de compreender os paradoxos engendrados pelo fenômeno da imaginação em suas históricas ambiguidades e aporias. Paul Ricoeur (1986) adverte para o "campo de ruínas" em torno dos estudos sobre a imaginação e interroga se seus paradoxos seriam um fracasso na filosofia da imaginação ou o traço estrutural da imaginação ela mesma.

Uma das resistências recorrentes ao pensamento imagético como pensamento encarnado é enfrentar a psicologia de inspiração behaviorista em seu esforço teórico de manter a imagem como entidade mental, privada, inobservável. Outra é a força popular de uma filosofia da criatividade cada vez mais capturada

\footnotetext{
8 Para Merleau-Ponty (1999a, p. 229), o pensamento encarnado é "uma operação primordial de significação em que o expresso não existe separado da expressão e em que os próprios signos induzem seu sentido no exterior. E dessa maneira que o corpo exprime a existência total, não que ele seja seu acompanhamento exterior, mas porque a existência se realiza nele. Esse sentido encarnado é o fenômeno central do qual corpo e espírito, signo e significação são momentos abstratos". É nesse sentido que o filósofo pode afirmar que "um movimento é aprendido quando o corpo o compreendeu, quer dizer, quando ele o incorporou ao seu "mundo", e mover seu corpo é visar as coisas através dele, é deixá-lo corresponder à sua solicitação, que se exerce sobre ele sem nenhuma representação" (Merleau-Ponty, 1999a, p. 193).
} 
pela ideia de comportamentos individuais de inovação e de produtividade. Uma ideia enraizada no âmbito psicológico informe da capacidade "inata" (ou "dom"), que contribui para o descrédito da imagem e da imaginação, já amplamente desqualificadas pelo histórico vínculo aos termos irrealidade, ilusão, ficção, delírio, fantasia, alucinação, os quais a racionalidade ocidental lhes retirou todo valor de incremento e produção de realidades.

Bachelard (1990, p.28) destaca que, na psicologia clássica, não há poder psíquico mais confusamente definido do que a imaginação ao constatar que além de não estudar a imagem poética, quando o faz a confunde com a simples metáfora. Para o fenomenólogo da imaginação poética, a compreensão de imagem é "um ponto de equívocos nas obras dos psicólogos: veem-se imagens, reproduzem-se imagens, guardam-se imagens na memória. A imagem é tudo, salvo um produto direto da imaginação" (Bachelard, 1989, p. 17). São interdições ao pensamento imagético que apontam para uma longa tradição filosófica sustentada na suspeita dos perigos da sensibilidade e da imaginação para o conhecimento do real.

Não há, neste "campo de ruínas", como desviar da pluralidade e abertura semântica do termo imagem, a qual permite uma grande variedade de definições e compreensões do fenômeno da imaginação nas abordagens filosóficas. Como afirma Wunenburger (2001, p. 5), o vocabulário latino é pouco sistemático em relação aos termos imagem, metáfora e alegoria que praticamente generalizam o procedimento de dizer uma coisa para significar outra. Em suas raízes grega (eikon) e latina (imago), os termos relacionados às imagens diferem na origem e na formação ${ }^{9}$ mas convergem no verbo "ver" e se relacionam intimamente aos termos "forma" como estrutura que acolhe uma matéria e "figura" como aspecto de uma matéria modelada (Richter, Kopp, 2019).

Porém, a maior dificuldade para a compreensão do pensamento imagético como pensamento encarnado está em tomar como pressuposto a polarização entre sujeito e objeto, ou seja, que as coisas são objetivas e os sujeitos subjetivos e a

\footnotetext{
9 Conforme Wunenburger (2001), em grego eikon remete a uma representação dada à vista, que reproduz com semelhança uma realidade; em latim, imago é uma forma, uma figura, um corpo, como, em alemão, Bild e Gestalt, em inglês, picture, figure, pattern, frame, shape.
} 
ação de desenhar na infância como iniciação aos segredos do mundo

linguagem mera intermediária entre ambos os polos. Bruno Latour (2007) contribui para compreender esse modelo ao sintetizar a ampla crença de que

existe um corpo, que significa um sujeito; existe um mundo, que significa objetos; e existe um intermediário, que significa a linguagem que estabelece as conexões entre o mundo e o sujeito. Se nós usarmos este modelo, acharemos muito difícil explicar o aprendizado por meio da dinâmica do corpo: o sujeito está "dentro" como uma essência definida, e aprender não é essencial para este vir a ser; o mundo está fora, e afetar os outros não é fundamental para a sua essência. Como para os intermediários - linguagem, kit de odores ${ }^{10}$ - que desaparecem uma vez que as conexões tenham sido estabelecidas, já que eles não fazem nada mais importante do que conduzir a ligação (Latour, 2007, p. 41).

Desse modelo decorre a tese quase imbatível, tanto para os filósofos realistas como para a generalidade dos psicólogos, de ser a percepção determinante dos processos de imaginação. Tese sustentada em uma concepção de conhecimento pautada em termos de causalidade da ação do sujeito sobre o objeto que encerra tanto o ato de perceber quanto o ato de imaginar na dependência da visão objetiva: ou das coisas (causas ativas do ver) ou dos olhos (que fazem as coisas serem vistas), seja ao explicar a percepção como síntese passiva das sensações causadas em nós pelas qualidades externas do objeto seja ao explicá-la como síntese subjetiva operada pelo sujeito que o organiza internamente pela reflexão.

Neste ensaio optamos por assumir a polissemia do termo imagem como fenômeno da mostração no qual as imagens produzidas pelas artes nos mostram algo a sentir-ver, nos colocam alguma coisa sob o pensar-olhar e sua demonstração procede de uma mostração. Para Nancy, o humano começou pelo saber dessa mostração.

De improviso, e com um mesmo primeiro gesto, faz aproximadamente vinte e cinco mil anos, o animal monstrans se mostra. Não mostraria nada se não se mostrasse a si mesmo ao mostrar. Mostra com um traço o estranho que ele é, mostra a estranheza do mundo ao próprio mundo, e mostra além disso seu saber da mostração e de seu estranhamento. Pois "mostrar" não é outra coisa que colocar à parte, colocar à distância de apresentação, sair da pura presença, ausentar e, assim, absolutizar (Nancy, 2008, p. 102).

${ }^{10}$ Latour (2007, p. 41) relata a experiência de como educar a sensibilidade do corpo para os aromas nas indústrias de perfume francesas a partir de um kit de odores (mallette à odeurs)"coextensivo ao corpo" nos quais os aprendizes "ganham um nariz". 
O que a imagem mostra, em sua ocorrência, é o modo como algo a nós se mostra e gera sentidos. Em suas tensões entre visibilidade e invisibilidade, na dinâmica de seu aparecer, a imagem ultrapassa o estritamente visível para mergulhar nas ambiguidades do invisível e questionar a visão sobre a existência de fronteiras entre o que se mostra e o que se oculta. Tal opção para abordar a plasticidade do termo imagem justifica-se pela compreensão de que as artes não dizem respeito ao mundo entendido como exterioridade, meio ou natureza. Antes, dizem respeito ao "ser no mundo em seu próprio surgimento" (Nancy, 2008, p. 31), no ato mesmo de partilhar visibilidades na indivisão do senciente-sensível de um corpo simultaneamente vidente e visível.

Partilhar visibilidades é ato sensível que faz nossa existência "ser em comum", isto é, que "ela é um 'ser/estar-com' ou com-partição" (Nancy, 2014, p. 57), a qual me significa ao me situar no mundo. Essa singular significação emerge da vida partilhada tecida pluralmente pela nossa co-implicação em um mundo comum ${ }^{11}$ (Garcès, 2013), ou seja, por aquilo que nos relaciona uns com os outros. E aquilo que nos aproxima uns com os outros é o sentido, ao mesmo tempo inteligibilidade, sensibilidade, sensualidade (Nancy, 2016, p. 19). Por essa compreensão, Tiburi e Chuí (2010, p. 10) em seu diálogo em torno da ação de desenhar, destacam as partilhas de sentido no plano dos afetos e dos desejos para afirmarem que "mesmo a mais mínima ação, como pode parecer a ação que leva a desenhar - tocam a todos nós. Sob o véu da estética subjaz o caráter político de toda experiência".

Nossa co-implicação em um mundo comum exige considerar que a complexidade política da experiência estésica, aqui dada pela ação poética de desenhar, tem a idade dos primeiros gestos humanos de transfiguração das coisas mundanas. Desde tempos imemoriais humanos manipulam gestos em linhas, cores, formas, texturas para articular sentidos e transformar o que existe a sua volta ao instaurar outras realidades, outros modos de sentir e narrar a coexistência. Nesse ato de transfigurar o mundo para atribuir sentido ao que

11 Compartilhamos com Garcès (2013) que a ideia de mundo comum não define uma totalidade, antes nos inscreve na continuidade do inacabamento do nosso devir e faz dela nossa situação, que o mundo não é a magnitude incomparável de uma soma mas a grandeza ou o valor de sua continuidade. 
ação de desenhar na infância como iniciação aos segredos do mundo

veem, ouvem e tocam com seu corpo, humanos partilham sensações e experiências na convivência. Transformam e produzem sentidos singulares para interagirem e coexistirem na pluralidade do mundo, para organizarem e marcarem a humana experiência mundana ali vivida, para torná-la inteligível, para permitir pensá-la com outros.

É desde o corpo senciente-sensível que Merleau-Ponty afirma a intersubjetividade como nossa intercorporalidade constitutiva ao nos convidar a pensar a dimensão comum e anônima da experiência “como um campo relacional que não nos dissolve mas que nos envolve e nos implica, que não nos uniformiza mas que precisamente é a condição de toda singularização" (Garcès, 2013, p. 131). Supõe compreender a impossibilidade de ser só um indivíduo como condição de exposição ao "nós", de um "nós" que não é um sujeito coletivo mas a dimensão comum de singularidades no e com o mundo. Essa, sublinha Garcés (2013, p. 49), é a condição para nos colocarmos "em situação", isto é, "para aprender a ver o mundo não mais desde o olhar frontal e focado no indivíduo, mas desde a excentricidade inapropriável, anônima, da vida compartilhada". Dimensão intersubjetiva que implica nos compreendermos desde nossa inscrição em um mundo que sou eu mesmo como um corpo entre os corpos, sejam coisas, humanos ou não-humanos, como vida entrelaçada a uma pluralidade de saberes e fazeres com dimensões comuns, tão distintas quanto artificiais, a qual não dominamos nem sequer conhecemos, mas que compõem minha existência, essa existência que somos nós e que é a condição material de nossas interações e processos de politização.

No pensamento merleau-pontyano, "nós" não é um pronome pessoal nem um sujeito plural, mas um sentido do comum que ultrapassa a relação entre pessoas ou a comunicação entre consciências singulares. Aqui, não há soma de "eus" mas uma operação de co-implicação de corpos (intercorporalidade ou intersubjetividade) que diz respeito à dimensão comum e anônima da experiência.

Nessa compreensão, assumimos o fenômeno da linguagem como potência inerente de um corpo tocar a outro corpo (de tocar-se) e "ser-com" (Nancy, 2006, p. 108). Por não estar além ou aquém do corpo sensível no e com o mundo 
comum, a experiência de linguagem implica a experiência da intersubjetividade como intercorporeidade, na qual os corpos - o meu e o de outrem - constituem "o verso e o reverso de um único fenômeno, e a existência anônima da qual meu corpo é a cada momento o rastro" (Merleau-Ponty, 1999a, p. 474). O fenômeno da linguagem excede o sentido de reconhecimento de mensagens ao constituir experiência existencial inseparável da experiência mundana de "viver-com", essa co-implicação de sermos "nós" - não como uma relação entre um eu e um tu, mas como dimensão fundante da vida anônima de instauração e transformação do mundo.

A relevância educacional em reivindicar maior atenção à experiência gestual de desenhar das crianças está em acolher com Aby Warburg (2015) que imagens são grandes sínteses de convivência humana. Convivência evocada, ritualizada e atualizada por figurações e por imagens que nos nutrem e nos situam na convivência mundana desde a mais tenra idade por ser a invisibilidade das imagens mais ampla e profunda que sua face visível.

\section{desenhar para tocar e ser tocado pelo mundo}

$\mathrm{O}$ ato de desenhar diz respeito a um impulso tão vital quanto lúdico que nos lança na produção de mundos, os quais logo passamos a acreditar. Basta o encontro com uma imagem, uma figuração ou um desenho para adentrarmos em uma visão ou uma narrativa oferecida à imaginação "capaz de nos fazer 'criar aquilo que vemos'" (Bachelard, 1988, p. 14). Acreditar, na fenomenologia bachelardiana da imaginação criadora, não implica apenas ter certeza, antes supõe reter em si as modificações provocadas pelas convicções que a obra tira de si mesma, "sem ser atormentada por censuras". (Bachelard, 1988, p. 154). Produzir mundos responde a uma necessidade de ficção operada pela "imaginação, capaz tanto de tornar algo perceptível, de reproduzir e de jogar com visibilidades, como de elaborar conceitos e teorias. Criar um 'mundo' é dar sentido, organizar o que acontece, transformar o acontecimento (simultâneo) em sucesso (temporal, sucessivo)" (Maillard, 2017). Nessa compreensão, produzir mundos responde a necessidade do real ser produzido em linguagem para ser pensado e é apenas 
ação de desenhar na infância como iniciação aos segredos do mundo

nessa referência produtora de sentidos comuns que a experiência humana, em sua dimensão temporal profunda, não cessa de ser refigurada.

A ação de desenhar permite ultrapassar os limites da realidade percebida em seu poder encarnado de valorar e significar o vivido pelo gesto transfigurativo do mundo em imagem ou mostração. Pelos devaneios da mão o traço designa

a transitividade do desenho que percorre os domínios da arte, da técnica e da ciência, costurando percepções e conceitos, dinamizando a inteligibilidade e a sensibilidade de pensamentos e ações engatados nas linhas que se projetam no espaço do mundo, provocando tessituras de significados sempre emergentes e em trânsito (Derdyk, 2007, p. 24),

Derdyk (2007, p. 21), ao destacar a ação de desenhar como desígnio disegno ${ }^{12}$ - sublinha não apenas a origem da palavra "desenho" nas línguas latinas mas o conflito que emerge de sua transitividade entre artes e ciências. Nesse sentido, a autora aponta para "a composição de diferentes acessos e experiências com e a partir do desenho -, projetando percursos inusitados para uma linguagem, tão antiga e tão permanente, em contínua resolução" (Derdyk, 2007, p. 17). O que permanece, desde tempos imemoriais, é o enigma do movimento estésico de passagem da invisibilidade do fundo corporal indecomponível à sensibilidade da singular expressão linguageira que se mostra, que faz aparecer algo para tornar-se presença no mundo.

Por ser um artifício figurativo, um ato ficcional ou um fazer-de-conta, - um fingere - dado por uma narrativa plasmada em traços, a ação de desenhar permite viver o prazer da experiência estésica de entrelaçar real e ficcional como movimento que densifica visões de mundo pela partilha do olhar. Partilha - que também é partição (Nancy, 2016, 2017) - de uma "visibilidade profana" (MerleauPonty, 2004) que tem que ser recriada no corpo.

Esse ato de recriação de uma visibilidade não se esgota no sensório - a vista ou o olho - mas exige a não-visibilidade como dimensão da profundidade do visível, o que prepara a visão para fazer ver e pelo qual o mundo torna-se visível.

12 Conforme Derdyk (2007, p. 21), citando Vilanova Artigas (1967), “o 'disegno' do Renascimento, donde se originou a palavra para todas as outras línguas ligadas ao latim, como era de esperar, tem os dois conteúdos entrelaçados, um significado e uma semântica, dinâmicos, que agitam a palavra pelo conflito que ela carrega consigo ao ser a expressão de uma linguagem para a técnica e de uma linguagem para a arte". 
Em Merleau-Ponty, a visão não é apropriação objetiva de relações regulares, "indeformáveis", mas aproximação sensível que implica transformações no corpo e no mundo. Somente um corpo separado de outro pode tocar e ser tocado, já que tocar surge da distância e da distinção de um e de outro e, portanto, a visão merleau-pontiana não capta imagens mas estabelece relações entre o visto e o não visto para nos ensinar que por ela

\begin{abstract}
tocamos o sol, as estrelas, estamos ao mesmo tempo em toda parte, tão perto das coisas longínquas como das próximas, e que mesmo nosso poder de nos imaginarmo-nos alhures, de visarmos livremente, onde quer que estejam, seres reais, esse poder recorre ainda à visão, reemprega meios que obtemos dela. Somente ela nos ensina que seres diferentes, "exteriores", alheios um ao outro, existem no entanto absolutamente juntos, em "simultaneidade" - mistério que os psicólogos manejam como uma criança maneja explosivos (MERLEAU-PONTY, 2004, p. 43).
\end{abstract}

Na fenomenologia de Merleau-Ponty (2004), misturar-se à luz, à cor, aos traços e às sombras exige aprender a tomar posse da visão. Luminosidade, cor, profundidade, não são comumente vistos pois existem ou são visíveis apenas em sua existência sensível, só estão aí "porque despertam um eco em nosso corpo, porque este as acolhe" (Merleau-Ponty, 2004, p. 18). Para torná-las visíveis é preciso aprender a ver para torná-la própria no ato mesmo de redobrá-la em outra visão: aquela que me faz ser visto de fora, que me instala no meio do visível. Ver como tocar ou mover-se - não emerge do pensamento ou do intelecto mas enraízase no corpo sensível que se sente ao sentir que sente. A visão se faz no meio das coisas, no mundo que em nós vem sentir-se, ali onde um visível se põe a ver e se vê vendo, co-presença que faz assistir a metamorfose do visível em vidente uma vez que "não se poderia tocar nem ver sem ser capaz de se tocar e se ver" (Merleau-Ponty, 1991, p.16). A visão se realiza num corpo situado no mundo, na qual a profundidade se dá como "distância vivida" porque ser corpo é estar atado a um certo mundo. Nosso corpo não está no espaço, ele é espaço, "vivo-o por dentro, estou englobado nele" (Merleau-Ponty, 2004, p. 33), assim como "estou em meu corpo, ou antes, sou meu corpo" (Merleau-Ponty, 1999a, p. 208).

O tocar-se, ver-se do corpo, em Merleau-Ponty (1999b, p. 226), "não é um ato, é um ser para". O enigma de ser meu corpo ao mesmo tempo vidente e visível (Merleau-Ponty, 2004, p. 17), não consiste em apreender-se como coisa, antes é abertura de si a si para perscrutar no corpo as sensações que suscita estar 
ação de desenhar na infância como iniciação aos segredos do mundo

inextricavelmente misturado ao mundo. $\mathrm{O}$ mundo não está à frente de mim, não o vejo segundo seu "invólucro exterior", eu o vivo em mim, estou nele e ele em torno de mim. Tocar e ser tocado pelo mundo não é atingir e ser atingido mas, distraidamente "escapar-se, ignorar-se" (Merleau-Ponty, 1999b, p. 226), é distanciar-se na dupla referência "de entrar em si e do sair de si, da vivência e da distância" (Merleau-Ponty, 1999b, p. 121).

A força poética da imaginação emerge da simultaneidade entre atenção e desatenção, entre visão focada e visão desfocada que estabelece relação entre o nítido e o vago, o visível e o invisível, na qual a distração relativa a um mundo é concentração relativa a outro mundo. Quando se entrevê a existência de mais algum real, a desatenção de um é concentração no outro. É o "ver como" da aparição. Em Octávio Paz (1982, p. 46), distração quer dizer "atração pelo reverso deste mundo". O olhar distraído resiste à nitidez do olhar focado que coloca o mundo diante de nós para deter-se na visão periférica desfocada em seu poder de "nos envolver na carne do mundo" (Pallasmaa, 2006, p. 10). Envolvimento que exige compreender que a visão periférica - ou háptica em sua capacidade de perceber o que está fora de foco - constitui a possibilidade de tocar e ser tocado pelo mundo. $\mathrm{O}$ tato - o tocar e ser tocado - é o sentido que integra nosso corpo com o mundo, e o faz em movimento, em um mundo que nos circunda. A periferia, nas palavras de Garcés (2013, p. 113), “excede nossa vontade de visão e de compreensão, na simultaneidade que lhes dá sentido porque as inscreve em um tecido de relações". Na periferia da visão, por não ser a distância contrária à proximidade, vigora uma atenção distraída que nos faz ver mais além do que aos olhos se apresentam.

É o que Bachelard (2002) reafirma ao destacar que na imaginação poética a qualidade das interações com o mundo não provém dos seus aspectos observáveis e conhecidos, mas do envolvimento com os valores que emergem desta interação. É a vontade de olhar para o interior das coisas que faz a visão aguçada, penetrante, para além do panorama oferecido aos olhos. Para Bachelard (2002, p. 28), a prospecção sugestiva ou o interesse subjetivo sobrepõe-se à inspeção objetiva, pois a percepção é antecipação e não lembrança. Vemos primeiro as 
coisas à distância onde nós as projetamos pela imaginação e não à distância onde as coisas efetivamente se encontram. A imagem imaginada "supre facilmente as insuficiências da percepção" (Bachelard, 2002, p.30) por ser valoração e não significação. Antes de ser figurada foi imaginada, situada no centro de um devaneio, na lentidão de um momento de atenção distraída de um olhar detido e despertado pelo mundo que quer se ver. Momento caprichoso porque pode ser detido ou abandonado.

Quanto às imagens desenhadas, do mesmo modo Merleau-Ponty (2002, p.186) argumenta que o desenho da criança, assim como do adulto, não pretende mostrar um sinal de identificação “objetivo" do que vê para comunicar-se com quem o olhará, pois "sua finalidade é marcar no papel um traço" de sua relação com as coisas. Aqui, não é dominante a visão objetiva, mas aquilo que despertou em seu corpo e a instalou no mundo, aquilo que fez vibrar seu olhar distraído e virtualmente seu tato, seus ouvidos, seu sentimento do acaso. A criança, ao desenhar, trata antes, "de dar um testemunho, e não mais de fornecer informações" (Merleau-Ponty, 2002, p. 186). O mundo presta testemunho de si mesmo na imagem que oferece ao corpo que o acolhe. É o tato imaginante que dá vida às qualidades adormecidas nas coisas, cujo efeito dura no tempo que durar o toque: "é o mesmo que dizer que a substância é dotada do ato de nos tocar. Ela nos toca assim como a tocamos, dura ou suavemente" (Bachelard, 1991, p.20). A materialidade mundana instrui o corpo no ato mesmo de manipular matérias muito diversas e bem particularizadas, promovendo em nós particularidades de flexibilidade e de decisão (Bachelard, 1991). As crianças adentram ao secreto das coisas pela possibilidade de manejar e transfigurar as diversas materialidades, em seus encontros com o mundo, desvelando o escondido, o oculto do mundo, pela insistência em ultrapassar as sensações primeiras.

A posse do mundo exige um faro tátil. A mão desperta a matéria e esta surge transfigurada pelo esforço do corpo sobre a resistência do mundo, na temporalidade do labor dos gestos no e com o mundo, os quais provocam devaneios tensos, íntimos e de admiração. Nos fazeres mundanos das crianças podemos compreender a potência da imaginação como esforço do corpo 
ação de desenhar na infância como iniciação aos segredos do mundo

manipular e produzir sentidos pela curiosidade agressiva e investigadora em relação ao que há para além do que pode ver. Os fazeres das crianças pequenas são simultaneamente tensos e curiosos pelo desejo de fazer aparecer algo que não sabe como pode aparecer.

Este jogo entre visível e invisível, entre corpo e visão imbricados pelo movimento no e com o mundo, mostram que a abertura do visível a outras visões é o não-visível da dimensão da superfície de uma profundidade inesgotável que "nasce sob meu olhar porque ele procura ver alguma coisa" (Merleau-Ponty, 1999a, p.354). Neste jogo, a ação de desenhar das crianças pequenas é marcada pelo acaso e o enfrentamento da presença do traço exige pensamento em ato. Exige das crianças disponibilidade para a exploração gestual, o esforço para a ação experimental de perseguir gestos que não sabem como terminará. A repetição ensina a realizar escolhas. Na repetição os gestos-traços recomeçam, retomam, reinventam-se em atualizações que vão engendrando figurações e repertórios gestuais e imagéticos no devir do movimento das diferenciações. Movimento transfigurativo que faz aprender a ver de outros modos, porque o repertório das crianças alterou-se e já não podem ver e ter as mesmas visões. Não são gestos superados pois duram em suas descontinuidades. Apenas por serem descontínuos, podem ser re-arranjados, podem começar e recomeçar "outra vez" para inaugurar outros gestos e outras marcas.

É pela historicidade do percurso temporalizado pelo ritmo do corpo que a ação de desenhar emerge como valoração da experiência no instante realizador da mão que traça seu modo de figurar para buscar como pode tornar visível a invisibilidade do mundo. Em Merleau-Ponty (1999b, p. 200; 232) “o visível está prenhe do invisível" e não é passível de ser tomado como o não-visível, como negativo-positivo do visível. O sentido é invisível, é “o não representável que me é apresentado como tal no mundo - não se pode vê-lo aí, e todo o esforço para aí vêlo o faz desaparecer, mas ele está na linha do visível, é a sua pátria virtual, inscreve-se nele (em filigrana)" (Merleau-Ponty, 1999b, p. 200). Essa relação entre visibilidade e invisibilidade, na ação de desenhar, exige um pensamento valorativo cujo critério é o que há por fazer no instante mesmo de contrastar o 
feito com o que resta a fazer a partir das escolhas e da valoração do que vai aparecendo na superfície do suporte. E as crianças o fazem com gestos rápidos para, talvez, rapidamente ir investigar o que pode haver no espaço ampliado de suas imagens. Imagens sempre sonhadas por um "olhar engrandecedor" que quer espreitar as coisas para habitá-las em suas brincadeiras e jogos.

Toda criança, ao desenhar, encontra em si mesma a potência de agir sobre o que produz, transformando tanto sua atenção no mundo como a atenção de seu corpo sensível pela possibilidade de o miniaturizar. A miniaturização permite trazer as coisas ao olhar pelos traços que promovem ampla abertura ao ficcional ao consentir outras e novas combinações que alteram a ordem das coisas favorecendo ações fora do alcance ou para sempre inatingíveis.

O encontro com a possibilidade de miniaturizar o vivido, mesmo que realizados com gestos rápidos, distraídos ou desatentos para alguns, não torna esta experiência menor ou menos intensa. É com a curiosidade de investigar o que pode haver no espaço ampliado de suas imagens que a criança transita e opera ritmos e tempos de adentrar nos segredos do mundo ao ultrapassar a lógica para poder "viver o que há de grande no pequeno." (Bachelard, 1989, p. 159). Imagens sempre sonhadas por um "olhar engrandecedor" que amplia e pluraliza gestos e marcas nos diferentes suportes. É pela miniaturização do mundo que a criança encontra a imagem e os objetos, em sua pequenez, e é neste mínimo, no detalhe das coisas grandes transpostas para a superfície do suporte, que atingem uma grandeza que amplifica sua presença no mundo e densifica modos de ver que renovam e ressignificam sentimentos de prazer e desprazer na multiplicação dos modos de ação pelo jogo. Diria Bachelard (1989) que os valores se engolfam na miniatura e fazem sonhar.

Na experiência de miniaturizar o mundo a criança - como o adulto - toca e é tocada pela distância do mundo. Neste gesto, a criança aprende a olhar atenta ao que lhe olha distraidamente. Dos traços lança-se à figuração, ao olhar que sente a distância para tornar-se gesto sempre diferente, sempre inaugural, mesmo que tenha total relação com a familiaridade dos gestos do seu corpo. Aqui, vigora a lei da repetição como diferenciação infinita. 
ação de desenhar na infância como iniciação aos segredos do mundo

Para Bachelard (1989, p.179), a miniatura do espaço vivido decorre exclusivamente das imagens da visão. A miniatura permite a composição das coisas díspares que se oferecem à nossa posse pela visão. A imaginação torna-se louca esperança de ver ao exigir atenção recorrente para integrar o detalhe: "Você não viu isso! Veja com calma todas essas coisinhas que não podem ser contempladas em seu conjunto" (Bachelard, 1989, p.167). O detalhe desafia a rapidez do olhar panorâmico ao fazê-lo confrontar as estranhezas do mundo familiar. A surpresa ou espanto coloca-nos diante de um mundo inaugurado, nos faz aprender que visto pela imaginação, o mundo é mutável e o tempo não é uniforme. "O lento não é o rápido freado. A lentidão é o demais, o exagero" (Bachelard, 1991, p. 22). O mais instigante, porém, é a magnitude do detalhe poético, a estesia das pequenas alegrias sensuais, para a aprendizagem da resolução de grandes questões: “quem aceita os pequenos espantos prepara-se para imaginar os grandes" (Bachelard, 19989, p. 120). Nessa afirmação, nada é insignificante para um pensamento aprendendo a dinamizar imagens e ideias, a alternadamente sonhar e pensar ao aprender a imaginar.

Mas, antes, é compreender que o pensamento imagético emerge de um corpo em situação no mundo, na sensibilidade aos detalhes como modo de apreciar a inteligibilidade inerente à qualidade das coisas. Desenhar é re-parar, é deter o olhar, é aquilo que Merleau-Ponty (2004, p.40) denominou de "um movimento sem deslocamento, por vibração ou irradiação" para interrogar se esse "movimento sem deslocamento" - se ele é vibração, irradiação, intensidade, pulsação, modulação - não é senão ritmo? Uma modulação do tempo que é a do percurso do olhar.

$\mathrm{O}$ ato de desenhar, desde os primeiros rabiscos das crianças, emerge do interesse estésico pela experiência lúdica de traçar linhas - pelo tempo da ação do gesto jogar com a ação de fazer aparecer algo em alguma superfície, e não pela chegada em algum resultado esperado. $\mathrm{O}$ valor estético e poético da experiência de desenhar emerge da intensidade do acontecimento temporalizado no corpo, pela travessia como atravessamento, como percurso mundano de um corpo que, ao ver que se vê, "não é pensamento de ver ou de sentir, mas visão" (Merleau- 
Ponty, 1999b, p. 226), sensível experiência muda do sentido mudo de adentrar na invisibilidade do mundo.

\section{desenhar como experiência muda de adentrar na invisibilidade do mundo}

Como a fita de Moebius, artes e infância jogam com a circularidade sem início e sem fim - infinita - do verso e do reverso entre a tensão ou inquietação e a disposição lúdica ou brincante de inaugurar sentidos. Essa produção, essa atenção estésica às qualidades mundanas, na qual tanto as decisões quanto as hesitações são formuladas no devir das metamorfoses do corpo em sua conquista de outros movimentos e gestos no mundo, diz respeito à potência poética da imaginação animar a linguagem e forjar brechas para a anima das coisas mundanas ao conferirlhes existência pela intimidade da experiência que o corpo faz delas e dele mesmo.

Desde começos imemoriais, humanos inauguram sentidos pela decisão de misturarem-se ao mundo. Nesse movimento, nos deparamos com a fecunda permanência da força poética linguagem como intencionalidade do corpo acessar sentidos pela atenção estésica às qualidades mundanas. Sons, cores, sabores, densidades, palavras, texturas e odores nos colocam no mundo e são por nós incorporados como "um multiverso de proposições articuladas" (Latour, 2007, p. 47), no qual as qualidades do mundo "estão na experiência que tenho dele e não em suas qualidades aparentes' (Merleau-Ponty, 1999a, p. 50). Implica compreender com Latour (2007, p. 46), que um corpo “articulado" é aquele que aprende a ser afetado pelas diferenças, isto é, um corpo vivo, sensível às qualidades mundanas em sua potência de fazer algo com elas e as transformar. Um humano desarticulado é indiferente e responde sempre do mesmo modo. Para um corpo vivo, “a realidade e a artificialidade são sinónimas, não antónimas. Aprender a ser afectado significa isso mesmo: quanto mais se aprende, mais diferenças existem" (Latour, 2007, p. 46).

O testemunho milenar apenas confirma a permanência da exigência polimorfa - ou multiversa - que nos impõe diferir mundos dançando, cantando, soando, traçando, tingindo. Essa exigência imperiosa poderia ser denominada, para Nancy (2008), de “infância”. Não como denominação de uma idade, mas 
ação de desenhar na infância como iniciação aos segredos do mundo

como uma eternidade difratada em cada instante, cada estado, cada cultura. As artes permanecem como infância que não esmaece ou perde a força, pois

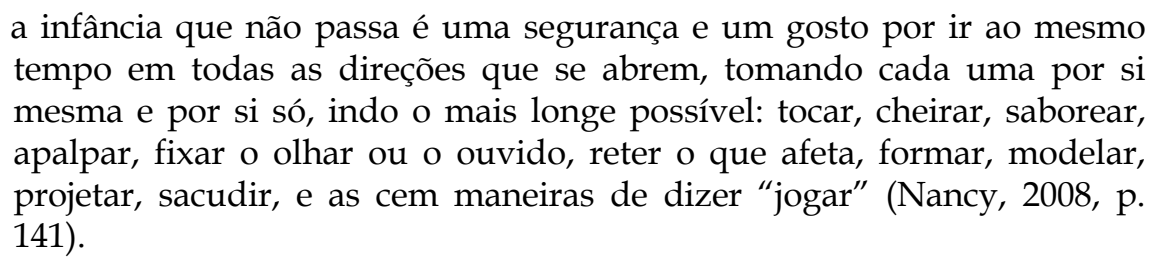

Cabe destacar que esta ideia está na contramão de constituir uma "infância das artes", pois, como afirma Nancy (2008), são as artes que são ou que constituem a infância e esta nos vai ao encontro, nos encontra até a velhice e a morte. Apenas o que permanece como valor pode ser jogado, transformado e atualizado. Aqui, “os fatos não explicam os valores. Nas obras da imaginação poética, os valores têm tal signo de novidade que tudo que deriva do passado é inerte com relação a eles. Toda memória precisa ser reimaginada" (Bachelard, 1989, p. 181).

A infância que nutre as artes é também a infantia que não fala - infans. Porém, assim como essa infância nos precede, essa ausência de fala constitui um excesso em relação à linguagem. Não como insuficiência ou inaptidão, mas como abertura de sentido ou acesso ao sentido. Mais do que uma ausência, é a condição de linguagem, o germe do pensamento em emergência, em vias de acontecer e que ainda não pode ser expresso. Aqui, o corpo sensível - que se sente sentindo, "é uma unidade plural de sentido" (Nancy, 2008, p. 142), um "sensível exemplar" (Merleau-Ponty, 1999b, p. 132).

É precisamente essa inefabilidade de ser in-fans (sem fala), essa existência inefável da linguagem, esse silêncio da mudez, que promove a experiência do pensamento "como abertura na qual e através da qual pode ocorrer o que pertence ao sentido, precisamente porque acontece, com sua força de anúncio, de chamada, ou de exigência" (Nancy, 2003, p. 11). Porém, como afirma Michel Serres (1993), mesmo quando a travessia do pensamento conduz a muito longe e muito alto, o que leva consigo é encarnado, ritmado, experimentado, suportado pelo corpo. Corpo que mobiliza sensações, nervos e músculos, tonaliza emoções, despende energias que vitalizam o ato de partilhar a existência.

A força instauradora de mundos pela linguagem, esse "mystérion que todo humano institui pelo fato de ter uma infância" (Agamben, 2005, p. 63), permite 
afirmar o ato de desenhar como ação estésica de tocar e ser tocado pelo mundo para apreendermos a potência poética da imaginação transpor os limites visíveis e adentrar na intimidade da invisibilidade mundana. Nessa afirmação, o importante é compreender que o mundo sensível não constitui um objeto para o pensamento mas a sua condição de possibilidade. A significação do mundo, em Nancy (2003, p. 74), implica "acolher o assombro ante o que se apresenta. Esta acolhida produz o pensamento". Condição que, na fenomenologia de Merleau-Ponty (1999a, p. 14), torna o mundo inesgotável, pois não é passível de posse, "não é aquilo que eu penso, mas aquilo que eu vivo". E viver - a conquista de sentido para o existir, não é outra que estar no existir mesmo pelo modo como nele nos inscrevemos.

O paradoxo humano está em ser apenas no aspecto aparentemente mais frágil e intangível da vida - a sensibilidade do corpo misturado ao mundo - que podemos compartilhar uma inefável reciprocidade de sentidos. A ludicidade do corpo linguageiro surge então como característica tanto do estado de inquietação quanto do estado de curiosidade que definem a humana necessidade de jogar com sentidos e que está na raiz sensível e intelectual de imaginar e aprender a perceber de outros modos o já vivido e conhecido. Paradoxo entre ludicidade e lucidez que traduz os perigos da linguagem e da visão.

O ato de ver, como ato de inextricável entrelaçamento entre corpo e mundo, merece a atenção educacional de todos os envolvidos com a experiência vital dos começos linguageiros das crianças. Considerar os fazeres das crianças como laboriosos processos de inserção na convivência mundana é destacar a relevância da escola como tempo e lugar que acolhe e convive com a infância como experiência lúdica de pensamento sempre em movimento estésico de se fazer. Mas é também interrogar como acolhe a ação de desenhar em diferentes suportes e com diversas materialidades que são o que definem os modos de aparecer das coisas, que ensinam os gestos a ver o que há de oculto no mundo. É este percurso, este processo temporal de constituição de uma visão encarnada pela ação de miniaturizar o mundo como aproximação tátil das coisas, na qual "os sonhos, os pensamentos, as lembranças formam um único tecido" (Bachelard, 1989, p. 180), que faz o processo de desenhar mais relevante que o seu resultado como desenho 
ação de desenhar na infância como iniciação aos segredos do mundo

finalizado. Aí ocorre o encontro com a magnitude de aprender a imaginar. É miniaturizando o mundo, na emergência entre o que há para ver e o que o gesto pode mostrar que a visão se constitui, e não com a contemplação da representação do desenho pronto, finalizado. Ver e mostrar é sempre um ato perigoso, pois ver algo significa sempre deixar de ver outra coisa. Estamos, humanos e mundo “numa comunhão de perigos. São perigosos um para o outro" (Bachelard, 1989, p. 182). Sabemos: o excesso de luz cega. Tudo ver, é nada especular. Nada a desenhar, a pintar, a cantar, a dançar. Nada a pensar.

\section{referências}

Agamben, Giorgio. Infância e história. Destruição da experiência e origem da história. Belo Horizonte: Editora UFMG, 2005.

Bachelard, Gaston. A poética do devaneio. São Paulo: Martins Fontes, 1988.

Bachelard, Gaston. A poética do espaço. São Paulo: Martins Fontes, 1989.

Bachelard, Gaston. Fragmentos de uma poética do fogo. Organização e notas Suzanne Bachelard. São Paulo: Brasiliense, 1990.

Bachelard, Gaston. A terra e os devaneios da vontade. São Paulo: Martins Fontes, 1991.

Bachelard, Gaston. Études. Présentation de G. Canguilhem. Paris: Librairie Philosophique J. Vrin, 2002.

Bachelard, Gaston. Ensaio sobre o conhecimento aproximado. Rio de Janeiro: Contraponto, 2004.

Baitello Junior, Norval. A era da iconofagia: reflexões sobre a imagem, comunicação, mídia e cultura. São Paulo: Paulus, 2014.

Castro, Manoel Antonio de. O mito de Cura e o ser humano. Calíope 19, 2009, Rio de Janeiro, p. 37-59. Disponível em: <https://dialnet.unirioja.es/servlet/articulo?codigo=3735090> Acesso 2 de fevereiro de 2020.

Derdyk, Edith (org). Disegno. Desenho. Desígnio. São Paulo: Editora Senac São Paulo, 2007.

Flusser, Vilém. Ensaio sobre a fotografia - para uma filosofia da técnica. Lisboa: Relógio D'água, 1998.

Flusser, Vilém. O universo das imagens técnicas: elogio da superficialidade. São Paulo: Annablume, 2008.

Galimberti, Umberto. Psiche e Techne: o homem na idade da técnica. São Paulo: Paulus, 2006.

Garcés, Marina. Un mundo común. Barcelona: Edicions Bellaterra, 2013.

Hillman, James. Cidade E alma. São Paulo: Studio Nobel, 1993.

Larrosa, Jorge. Linguagem e educação depois de Babel. Belo Horizonte: Autêntica, 2004.

Latour, Bruno. Como falar do corpo? A dimensão normativa dos estudos sobre a ciência. In: Nunes, J. A.; Roque, R. (Org.). Objetos impuros: experiências em estudos sociais da ciência. Porto: Afrontamento, 2007. p. 40-61. Disponível em: <http://www.brunolatour.fr/sites/default/files/downloads/77-BODY-NORMATIVE-POR.pdf > Acesso em 25 de janeiro de 2020.

Maillard, Chantal. La razón estética. Barcelona: Galaxia Gutenberg: Edición en formato digital: septiembre 2017. Disponível em:

<https://www.academia.edu/39316975/La_raz\%C3\%B3n_est\%C3\%A9tica__Chantal_Maillard> Acesso em 30 de janeiro de 2020. 
Matisse, Henri. Escritos e conversas sobre arte. In: Lichtenstein, Jacqueline (Org.). A pintura. Vol. 6: A figura humana. São Paulo: Editora 34, 2004, p. 117-126.

Merleau-Ponty, Maurice. Signos. São Paulo: Martins Fontes, 1991.

Merleau-Ponty, Maurice. Fenomenologia da percepção. São Paulo: Martins Fontes, 1999a.

Merleau-Ponty, Maurice. O visível e o invisível. Prefácio e posfácio de Claude Lefort. São Paulo: Perspectiva, 1999b.

Merleau-Ponty, Maurice. A prosa do mundo. Edição e prefácio de Claude Lefort. São Paulo: Cosac\&Naify, 2002.

Merleau-PontY, Maurice. O olho e o espírito: seguido de A linguagem e as vozes do silêncio e A dúvida de Cézanne. Prefácio Claude Lefort; posfácio Alberto Tassinari. São Paulo: Cosac \& Naify, 2004.

Nancy, Jean-Luc. El olvido de la filosofía. Madrid: Arena Libros, 2003.

Nancy, Jean-Luc. Ser singular plural. Madrid: Arena Libros, 2006.

Nancy, Jean-Luc. Las Musas. Buenos Aires: Amorrortu, 2008.

Nancy, Jean-Luc. El arte hoy. Ciudad Autónoma de Buenos Aires: Prometeo Libros, 2014.

Nancy, Jean-Luc. Demanda. Literatura e filosofia. Florianópolis: Ed. UFSC; Chapecó: Argos, 2016.

Nancy, Jean-Luc. Arquivida. Do senciente e do sentido. São Paulo: Iluminuras, 2017.

Nancy, Jean-Luc. La posibilidad de un mundo. Diálogo con Pierre-Philippe Jandin. Traducción de Isidro Herrera. Madrid: Arena Libros, 2019.

Pallasmaa, Juhani. Los ojos de la piel. Barcelona: Gustavo Gili, 2006.

Paz, Octávio. O arco e a lira. Tradução Olga Savary. Rio de Janeiro: Nova Fronteira, 1982.

Richter, Sandra R. S. A dimensão ficcional da arte na educação da infância. Faculdade de Educação, Universidade Federal do Rio Grande do Sul, Porto Alegre, 2005. Tese de Doutoramento.

Richter, Sandra R. S.; Kopp, Felipe A. Imaginação em Sartre e Bachelard. Kinesis, Vol. XI, n 30, dezembro 2019, p.38-61.

Ricouer, Paul. Du texte à l'action: essais d'herméneutique II. Paris: Éditions du Seuil, 1986.

Sennett, Richard. Artesanía, tecnología y nuevas formas de trabalho. Seguido de "Hemos perdido el arte de hacer ciudades" (entrevista de Magda Anglès). Buenos Aires: Katz Editores; Barcelona: Centro de Cultura Contemporánea de Barcelona, 2013.

Serres, Michel. Variações sobre o corpo. Rio de Janeiro: Bertrand Brasil, 2004.

Serres, Michel. Filosofia mestiça. (Le Tiers-Instruit). Rio de Janeiro: Nova Fronteira, 1993.

Tiburi, Marcia; Chuí, Fernando. Diálogo/Desenho. São Paulo: Editora Senac São Paulo, 2010.

Valéry, Paul. Primeira aula do curso de poética. In: Variedades. São Paulo: Iluminuras, 1999, p. 179-192.

Warburg, Aby. Histórias de fantasma para gente grande. Escritos, esboços e conferências. São Paulo: Companhia das Letras, 2015.

Wunenburger, J. J. Philosophie des images. 2. ed. Paris: Presses Universitaires de France, 2001.

recebido em: 07.02.2020

aprovado em: 11.04 .2020 